\title{
Miniaturization In Rational Drug Design of Pharmaceuticals : A Review
}

\section{GHAZALA YASMEEN, MOHD. IBRAHIM ${ }^{1}$, V.MURLI BALRAM ${ }^{2}$, S.IMAM PASHA ${ }^{3}$, SADAF RAHMAN and MOHSINA ABID}

${ }^{1}$ Prof. \& Principal, Nizam Institute Of Pharmacy, Nalgonda T.S India.

${ }^{2} \mathrm{Hod}$, Department Of Pharmaceutical Analysis \& Quality Assurance,

${ }^{3}$ Asst. Professor Department of Pharmaceutical Analysis \& Quality Assurance, Sultan-UI-Uloom College of Pharmacy, Banjara Hills, Hyderabad-500034, TS, India.

${ }^{*}$ Corresponding author E.mail: impazam @gmail.com

http://dx.doi.org/10.13005/ojc/320254

(Received: November 26, 2015; Accepted: December 30, 2015)

\begin{abstract}
Miniaturization in High Throughput Screening (HTS) is perceived as essential by pharmaceutical screening laboratories to accommodate the enormous increase in compounds and targets over the past few years. The two primary goals are to increase throughput while decreasing costs. The ability to perform primary screening assays in high-density micro-well plates at volumes of $1-2 \mu \mathrm{l}$ will accelerate the early stages of drug discovery. Ultra-HTS (uHTS) assays require an accurate and reliable means of fluid handling in the submicroliter volume range. This relates to the design of instrumentation for dispensing fluids, as well as assay plates. Fluid handling has been a major obstacle to the full implementation of miniaturized assays. This report focuses on current approaches to submicroliter fluid handling in high-density multi-well plates.
\end{abstract}

Keywords: Miniaturization, Drug design, pharmaceuticals.

\section{INTRODUCTION}

In early phases of development, only small amounts of the active pharmaceutical ingredient (API) are available. With difficult drugs however, many different formulations are necessary to achieve adequate bioavailability. Therefore, low API consumption for each formulation creates a substantial developmental advantage. This can be achieved by miniaturized equipment for the most relevant pharmaceutical technologies. Until a few years ago, the commercially available equipment required minimal batch sizes of $50-100 \mathrm{~g}$ for nearly all formulation technologies. Number of small scale equipment increased considerably in the meantime, but in most cases, the basic technologies are still designed for large scales, only the formulation part is smaller. Therefore, this equipment is still very expensive, heavy, and requires a lot of lab space and cannot be located easily into containments which is necessary for toxic or highly active APIs. Therefore, miniaturized equipment for the most 
relevant formulation technologies of oral dosage forms was developed at the group new technologies of Boehringer Ingelheim (BI).

The need to discover new pharmaceuticals Rapidly and at a lower cost continues to change. The way drug discovery is practiced within the Pharmaceutical industries. Increasingly, drug developers are confronting the need to streamline their processes, improve the robustness of their screening operations and enhance the quality of early development candidates. HTS of large collections of compounds against therapeutic targets is increasingly employed as part of an early-stage strategy for identifying active chemo types, which can eventually be developed into marketable drugs. The number of compounds screened in HTS laboratories runs into the millions3. As the number of therapeutic targets increase, so will demand for HTS, creating pressure to improve efficiency. Ultra-HTS (huts), in which more compounds are screened at lower cost and in less time, has been a major goal. The expansion of the role of UHTS in the drug development process creates the need for new technologies. Technology that enables the miniaturization of screening assays has been one route towards accomplishing $\mu \mathrm{HTS}$. Miniaturized assays consume less reagents and compounds, and reduce the cost of screening. Miniaturized assays can also be performed faster and therefore reduce the time required to complete primary screens.

Assay miniaturization has followed an evolutionary process, starting with the movement of tests away from milliliter volumes in test tubes, and towards micro liter volumes in the standard 96- well micro-plate format ${ }^{1}$. This evolution has continued with the increased utilization of 384-well plates, which enables assays to be performed in the range of $10-20 \mu l$. The next logical step is the development of assays in the submicroliter volume range. Assays performed in 1536-well plates at volumes of < 2 $\mu \mathrm{l}$ would significantly reduce the cost and time of screening. The greatest impact would be for screens performed with very large compound collections ${ }^{2}$. Specific challenges to the implementation of a miniaturized screening platform based on the use of 1536-well plates include the development of instruments for detection and fluid handling.
Miniaturized assays performed at volumes of $2 \mu \mathrm{l}$ or less require fluid handling equipment capable of operating reliably in the submicroliter volume range. Assay plates also need to accommodate the volumes. Many of these challenges are being actively pursued by the suppliers of screening instruments and commodities. Detectors capable of reading 1536-well plates have been on the market for more than an year now. Although dispensers capable of working in the submicroliter volume range are available now, fluid handling remains the greatest barrier to implementation of miniaturized $\mathrm{uHTS}^{3}$.

This article describes the problems and challenges associated with fluid handling for miniaturized $\mu \mathrm{HTS}$. The focus will be on approaches that have been undertaken to develop instruments for fluid handling in the submicroliter volume range. We will also discuss the impact of plate design for assay miniaturization in regard to fluid handling at these volumes.

\section{Current status of knowledge}

As HTS progresses into the next century, a concomitant consolidation of the complex synergy between associated developments in chemistry, biology, engineering and informatics for lead discovery is necessary. It is anticipated that, in addition to providing innovative solutions to technological challenges, this consolidation must also enable incorporation of $\mu \mathrm{HTS}$ technologies into the infrastructure of the pharmaceutical industry.

It has been estimated that industrial screening demands will require the number of new Chemical entities introduced per year are to be tripled, necessitating a threefold increase in the speed of current screening technology. Miniaturization provides as a key sourse of keeping and maintaining the constant pace with genomics because it enables proportionately more targets and samples to be screened per unit time. Because of the small amounts of compounds and reagents used in the miniaturized system, this increase in screening speed can be achieved without an increase in associated R\&D costs ${ }^{4}$. As a result of the benefits mentioned previously, miniaturization setss a key foundation of screening philosophy. 
Table 1: Advantages and disadvantages of miniaturized uHTS

\begin{tabular}{|c|c|c|}
\hline $\begin{array}{l}\text { M miniaturized } \\
\text { Features uHTS Key }\end{array}$ & Positive & Negative \\
\hline \multirow[t]{4}{*}{ Compound logistics } & Saving of precious compounds & $\begin{array}{l}\text { Reformatting step from } \\
96,384 \text { to e"1536-well } \\
\text { plates necessary }\end{array}$ \\
\hline & High-density storage possible & \\
\hline & Potential for automated fractionation of natural & \\
\hline & Extracts into screening plates & \\
\hline Assay miniaturization & Saving precious target or legend & $\begin{array}{l}\text { Necessary effort because } \\
\text { of altered surface: volume } \\
\text { ratio and evaporation } \\
\text { issues(adsorption effects) } \\
\text { in high-density formats } \\
\text { Solution: Bench top } \\
\text { workstations for assay } \\
\text { development, consisting of } \\
\text { the same liquid-handling } \\
\text { hardware as screening } \\
\text { devices necessary for assay } \\
\text { compatibility tests }\end{array}$ \\
\hline \multirow[t]{2}{*}{ Plate formats } & $\begin{array}{l}\text { High compound density (less process steps, } \\
\text { more parallelization) allows enhanced } \\
\text { throughput } 1536 \text {-well plates already } \\
\text { compatible with many systems }\end{array}$ & $\begin{array}{l}\text { Increased demand on plate } \\
\text { manufacturing } \\
\text { Precise plate adjustment in } \\
\text { dispensing and reading }\end{array}$ \\
\hline & $\begin{array}{l}\text { Plates of } 2080 \text { and } 3456 \text { wells already } \\
\text { routinely applied }\end{array}$ & System necessary \\
\hline Liquid handling & $\begin{array}{l}\text { Precise and reliable nanoliter handling with } \\
\text { piezoelectric drop-on-demand systems } \\
96 \text { or } 384-\text { Well parallel dispensing enhances } \\
\text { velocity of assay assembly }\end{array}$ & $\begin{array}{l}\text { Cell handling difficult, } \\
\text { but possible }\end{array}$ \\
\hline Detection systems & $\begin{array}{l}\text { Confocal detection independent } \\
\text { of miniaturization. Imaging technologies } \\
\text { applicable to fast } 1536 \text {-well reading } \\
\text { Fast } 96 \text { or } 384 \text {-well parallel reading }\end{array}$ & $\begin{array}{l}\text { Restricted to fluorescence } \\
\text { or luminescence based } \\
\text { readouts M macroscopic } \\
\text { fluorescence sensitive to } \\
\text { miniaturization }\end{array}$ \\
\hline Automation & $\begin{array}{l}\text { Fully automated screening platforms } \\
\text { (integrated or modular) available for screening } \\
\text { in } 1536,2080 \text { or } 3456 \text {-well plates }\end{array}$ & $\begin{array}{l}\text { Sealed humid atmosphere } \\
\text { as protection against } \\
\text { evaporation necessary }\end{array}$ \\
\hline Data management & $\begin{array}{l}\text { Automation of data handling is } \\
\text { worthwhile because of high data amounts }\end{array}$ & $\begin{array}{l}\text { Increased efforts in } \\
\text { database administration } \\
\text { and data mining }\end{array}$ \\
\hline
\end{tabular}


Combining miniaturized technology with developments in automation, sensitive signal detection, plate formats, automated compounddelivery and data management results in high efficiency, and cost-effective, integrated miniaturized $\mu \mathrm{HTS}$ systems. This review will concentrate on the recent major developments that have occurred in the $\mu \mathrm{HTS}$ arena over the past few years. Adaption of assay designs for $\mu \mathrm{HTS}$ running conditions will also be discussed.

\section{Assay miniaturization}

Assays present a significant demand On $\mu \mathrm{HTS}$ systems. Established biochemical Assays should be readily adaptable to miniaturized formats to shorten overall screening cycle-time. Lab-on-achip and micro scale total analysis systems are highly miniaturized ${ }^{5}$. Such systems promise assay volumes at the peculator level and throughputs that will easily exceed 100,000 assays per day. In addition to increasing assay throughput by incorporating low volume, high density formats, further improvements can be achieved through the use of multiplexing strategies.

Multiplexing involves the detection of multiple screening-parameters simultaneously or in rapid sequence; these parameters might include the fluorescence polarization, intensity, lifetime and emission wavelength of a single or multiple species ${ }^{6}$. In many target classes, it is now possible to design assay systems that involve mixing the components, incubating to a suitable end-point or equilibrium and measuring a detection signal. This homogeneous 'mix and measure' type of assay is ideal for HTS. Functional cellular assays in miniaturized format are increasing in importance as primary screening assays ${ }^{7}$. Although cell-based assays using reporter genes have proved effective as a $\mu \mathrm{HTS}$ format, detecting more immediate responses to targetprotein activation provides several advantages, including shorter assay duration and fewer falsepositives from non-specific interactions. Recent advances in miniaturization technology and molecular biology have made it possible to monitor, for example, the presence of second messengers (Ca2+, camp, instill triphosphate), phosphorylation of intermediate signaling molecules or sub cellular translocation ${ }^{8}$. Assay miniaturization is the process of establishing optimal assay conditions for the microliter volume range that is necessary for the screening of high-density-well plates, thus minimizing reagent consumption and reducing storage capacity (Table 1). Several issues need to be tackled during assay miniaturization:

- $\quad$ Appropriate and accurate liquid handling (e.g. dispensing of cells through narrow-bore pipettes presents particular difficulties);

- $\quad$ Minimizing evaporation effects;

- $\quad$ Ensuring comparable assay sensitivity (dynamic range, binding constant $\mathrm{K}_{\mathrm{id}}, \mathrm{IC}_{50}$ ) and screening statistics;

- $\quad$ Tackling the increased surface : volume ratio, which increases adsorption effects;

- $\quad$ Reproducing the conditions to be encountered on the HTS system as closely as possible (i.e. tackling issues such as reagent stability, kinetics of enzyme reactions. and sedimentation and viability of cells); and

- Using full high-density-plate layouts in assay development and assay miniaturization? ${ }^{9}$.

Solutions to overcome these problems at the nanoscale level include altering the concentration and/or the order of addition of assay reagents (e.g. by adding 'sticky' reagents last) and adding detergents that reduce non-specific binding in a typical concentration range between $0.01 \%$ and $0.5 \%$. Automated assay optimization (AAO), which takes advantage from the statistical design of experiments (DOE), is a key method in the reduction of assay parameters and is ideal for application to high-density-plate formats. If used properly, AAO enables uHTS laboratories to reduce assay optimization timelines and to optimize 'throw away' assays that would not be a subject of a screening run under usual conditions.

The translation of assay protocols from assay development via assay miniaturization to the $\mu \mathrm{HTS}$ platform is a challenge that must not be underestimated. The use of bench top workstations with hardware components identical to those installed within the $\mu \mathrm{HTS}$ system is the key factor for running a huts factory successfully ${ }^{10}$.

\section{CONCLUSIONS}

As the components for assembling a miniaturized $\mu \mathrm{HTS}$ laboratory are becoming available now, 
screening of large compound collections in assays using volumes of $1-5 \mu$ are now becoming practical. Crucial components include fluid-handling instrumentation and assay plates. Technology for dispensing fluids at volumes of $>50 \mu$ is being developed. Instrument manufacturers are beginning to offer fluid-handling instruments capable of operating in this range. In addition, manufacturers are marketing 1536-well plates that can be used for $\mu \mathrm{HTS}$ assays at such volumes. At Pharmacopeia, we have successfully utilized technology based on both contact and non-contact fluid transfer in our uHTS laboratory.
As these tools continue to be developed and improved, miniaturized $\mu \mathrm{HTS}$ will become regular practice in screening laboratories. The benefits that will be achieved include reduced cost of primary screening and time required to identify lead compounds. These will be important factors as more new therapeutic targets are identified and the demand for uHTS becomes greater.

\section{ACKNOWLEDGEMENT}

Sultan-UI-Uloom College Of Pharmacy, Banjara Hills, Road No.3, Hyderabad-500034 for providing all the facilities.

\section{REFERENCES}

1. Kenny, B.A. The application of high-throughput screening to novel lead discovery. Prig. Drug Res., 1998,51, 245-268.

2. Bureau, J.J. Whither high-throughput screening Drug Disco. Today 5 (Suppl. Highthroughput Screening).,2000,1-2.

3. Fox, S.J. High-Throughput Screening; Trends In Assay Development, High-tech Business Decisions., 1999.

4. Sittampalam, G.S. High-throughput screening: advances in assay technologies. Curr. Opin. Chem. Biol.,1997, 1,384-391.

5. Nakayama, G.R. Micro plate assays for highthroughput screening. Curr. Opin. Drug Disc. Dev.,1998, 1, 85-91.

6. Hill, D.C. Trends in development of highthroughput screening technologies for rapid discovery of novel drugs. Curr. Opin. Drug Disc. Dev.,1998, 1, 92-97.

7. Burbaum, J.J. and Sigal, N. New technologies for high-throughput screening. Curr. Opin. Chem. Biol.,L 1997, 1, 72-78.

8. Huston, J.G. and Banks, M. The chemicalbiological interface: developments in automated and miniaturized screening technology. Curr. Opin. Biotechnol.,1997, 8,736-740.

9. Burbaum, J.J. The evolution of miniaturized screening. J. Biomol. Screening.,2000,5,5-6.

10. Burbaum, J.J. Miniaturization technologies in
HTS: how fast, how small, how soon? Drug Discov. Today.,1998,3,313-3.

11. Shireen Mohammed, Maher Khalid, Orient. J. Chem.,2015, 31(3),1319-1326.

12. Rahbar, M.; A. Morsali, M.; Bozorgmehr, R.; Beyramabadi, S. A.; Orient. J. Chem. 2015, 31(3), 1403-1407.

13. Azadeh Nazarian,, Orient. J. Chem. 2015, 31(3), 1477-1488.

14. Uttam Prasad Panigrahy, Sunil Kumar Reddy, A.; Orient. J. Chem.,2015,31(3), 1489-1507.

15. Mansoorinasab, A.; Morsali, A.; Heravi, M.M.; Beyramabadi, S. A.,Orient. J. Chem. 2015, 31(3),1509-1513.

16. Manal Hamed, M.; Samir El-Amin, M.; Laila Refahy, A.; El-Sayed Soliman, A.; Wafaa Mansour, A.; Hoda Abu Taleb, M.; Eman Morsi, A. Orient. J. Chem., 2015, 31(3), 16211634.

17. Saman Khaledian, Saadi Saaidpour, Orient. J. Chem. 2015,31(3), 1969-1976.

18. Sarath Chandran, I.; Pichandy Muthu Prasanna, Orient. J. Chem.,2015,31(3),22012206.

19. Elham Shabanzadeh, Roghiehtarlanibashiz, Orient. J. Chem.,2015,31(3),2461-2468.

20. Mayukh Baidya, Amit Kumar Das, Orient. J. Chem., 2015,31(3),173-178.

21. Ramesh, C. Nagarjuna Reddy,G. Narayana, Tv.Prasada Rao, K.V.S. Ganga Rao, B. Orient. J. Chem., 2015, 31(3),313-316. 